\title{
Glucocorticoid Receptor is distinct from Androgen Receptor function in Castrate-Resistant Prostate Cancer
}

\section{ROOSEVELT UNIVERSITY}

\section{Background}

Prostate cancer is the most common cancer among men in the United States. Diagnosis and treatment:

PC is diagnosed by needle biopsy.

Laparoscopic prostatectomies are treatments for localized $P C$

For metastatic PC, Androgen-Deprivation Therapy (ADT) is used to inhibit AR pathways. Castate cancer cells develop resivtance to ADT and become Castrate-Resistant Prostate Cnzalutamide is ineffective in some patients, and resistance to Enzalutamide develops rapidly often leading to death.

Novel treatments for CRPC are critically needed.

In a subgroup of CRPC patients, glucocorticoid receptor (GR) is highly expressed and active. GR can drive the growth of CRPC when AR is blocked, mimicking AR activity.

Therapies directed against GR-driven growth may be successful in treating CRPC.

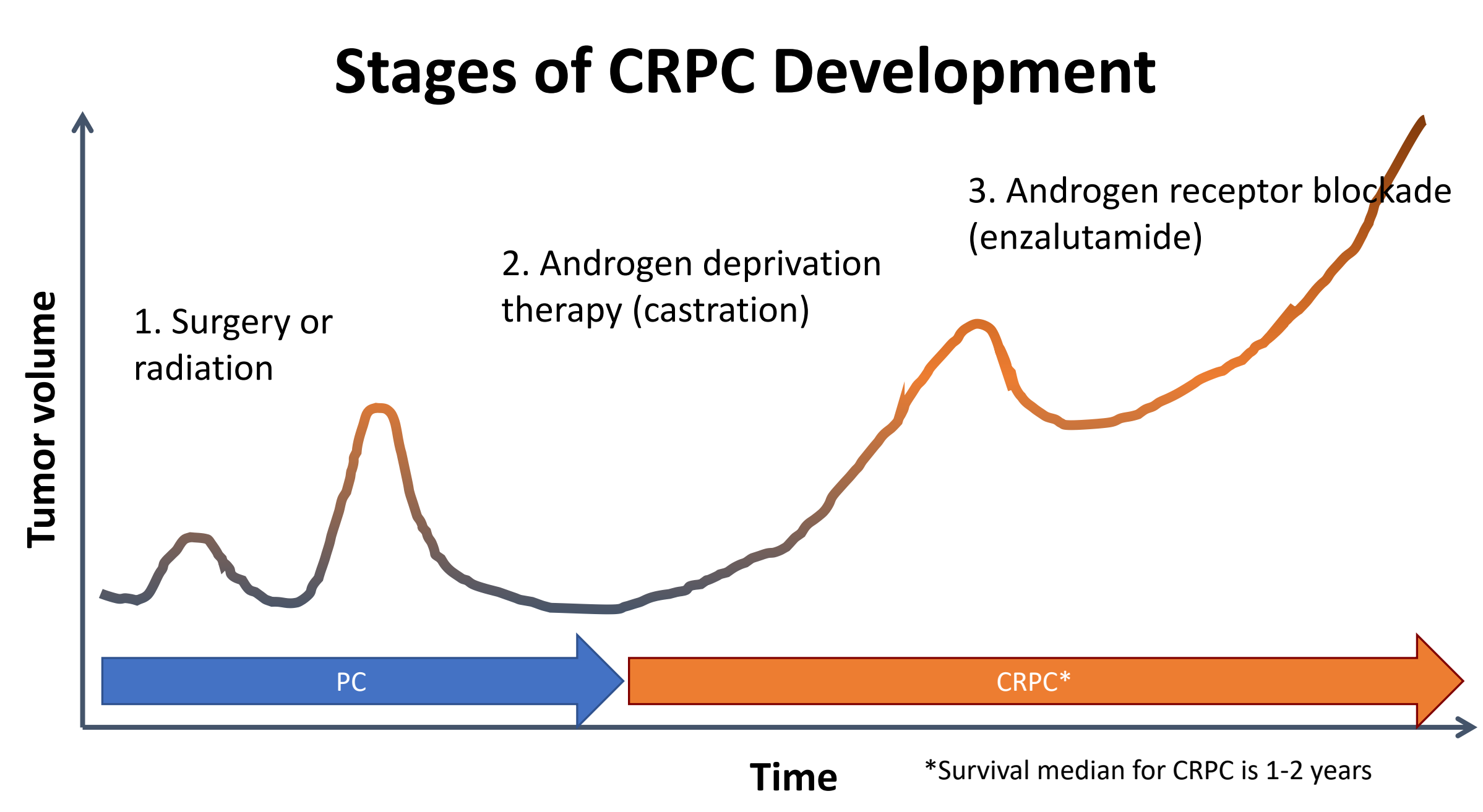

Glucocorticoid receptor (GR) activity can recapitulate androgen receptor (AR) function in CRPC

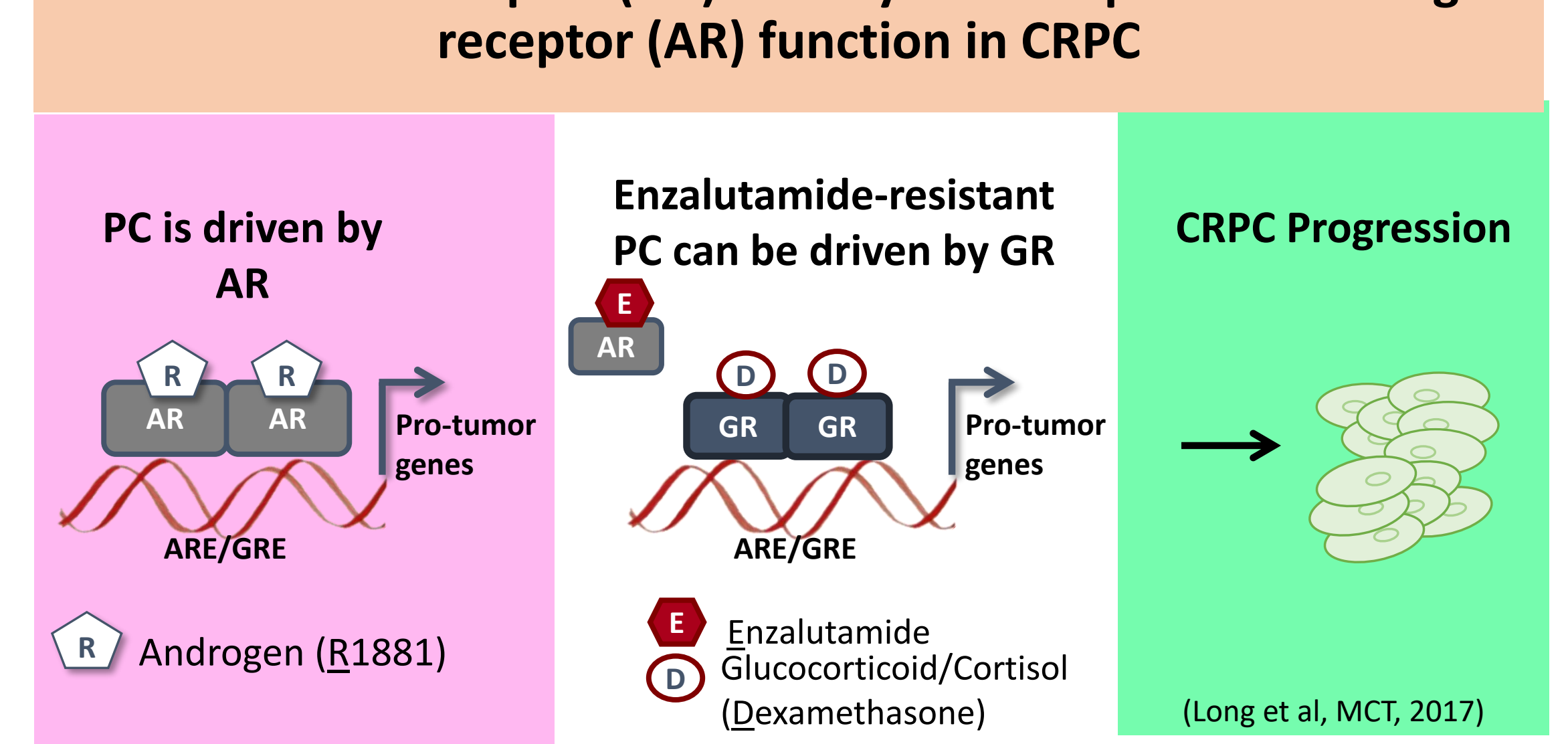

Background Figure 2. GR is able to recapitulate AR function in AR-blocked prostate cancer.

Enzalutamide blocks AR activity
The addition of Dexamethast

\section{Hypothesis}

It is unknown if GR has unique activities in CRPC other than recapitulating AR

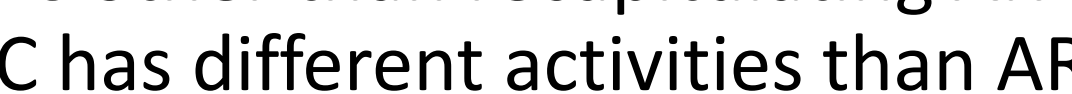
that promote progression to metastatic disease.

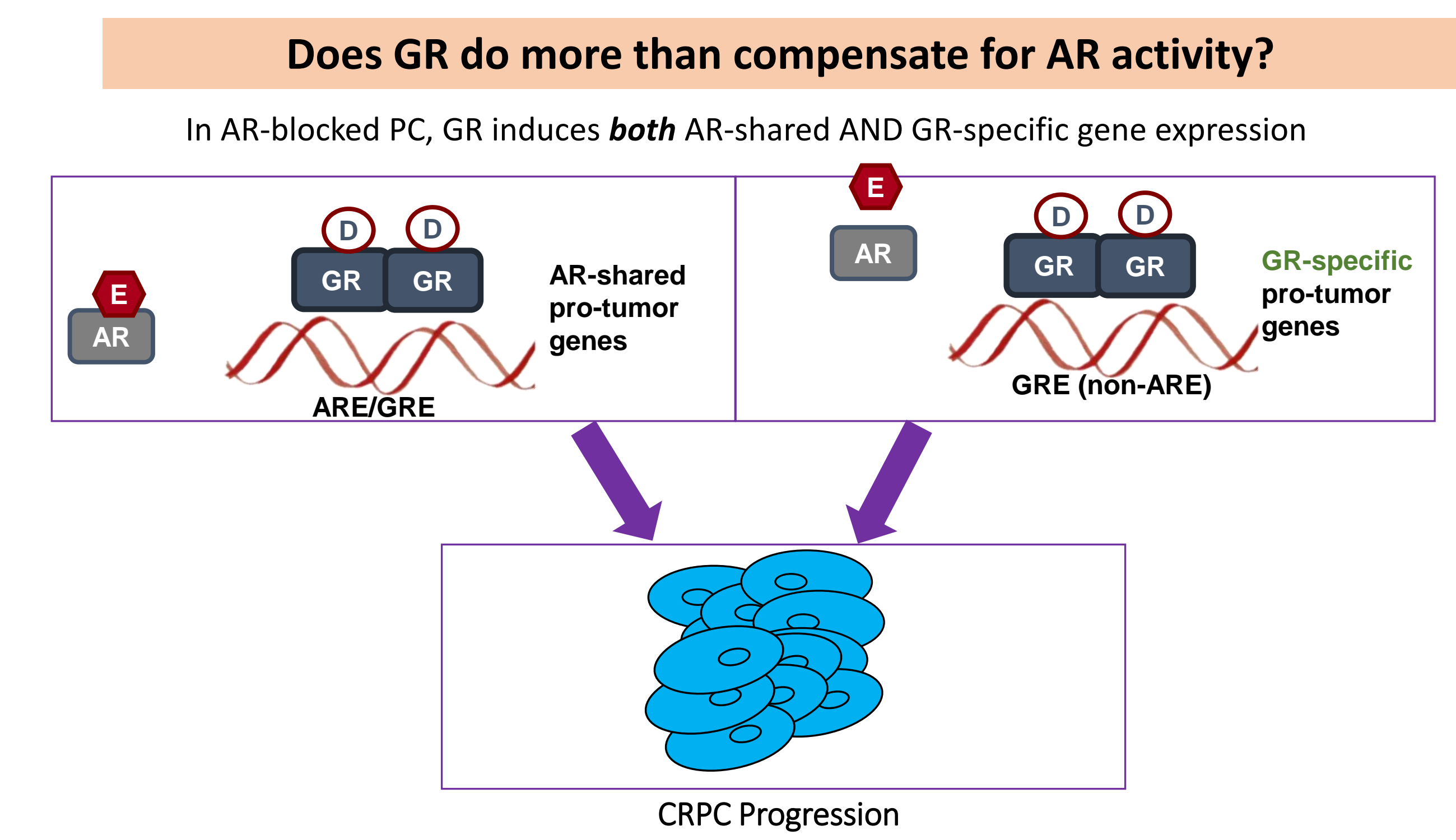

Background figure 3. Hypothesis: GR carries out additional functions compared to AR to drive CRPC progression.
Dalal El-Barbarawi ${ }^{1}$, Tiha M. Long, $\mathrm{PhD}^{1}$

1.Roosevelt University, Chicago IL

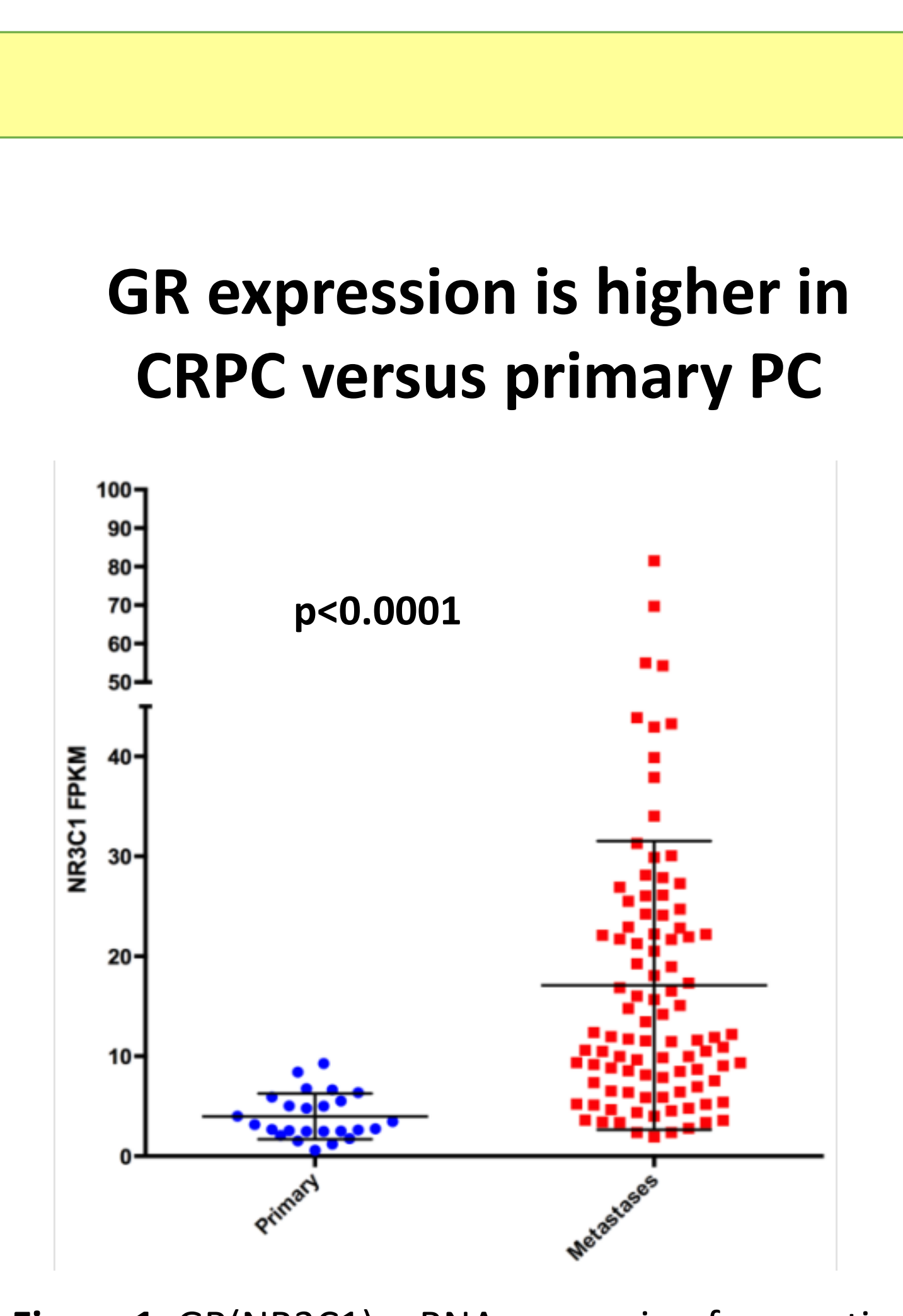

Figure 1. GR(NR3C1) mRNA expression from patient

sample cohorts. (unpublished Long et al.)

\section{Results}

Many genes induced by Androgen and Glucocorticoid do not overlap

$$
\begin{array}{cc}
\text { R vs V } & \text { RED vs RE } \\
\mathrm{N}=7593 & \mathrm{~N}=6658
\end{array}
$$

532

$\stackrel{2264}{2} \stackrel{4394}{\text { (shared) }}$

Figure 2. CRPC cells (CWR-22Rv1) were treated with Androgen (R), +/Enzalutamide (E), + - Dexamethasone (D)) for 72 hours. RNA was collected from cells and total mRNA was sequenceed. Differential genes expression was
determined for Vehicle vs R and RED $y$ R RR. (unpublished Long et al)

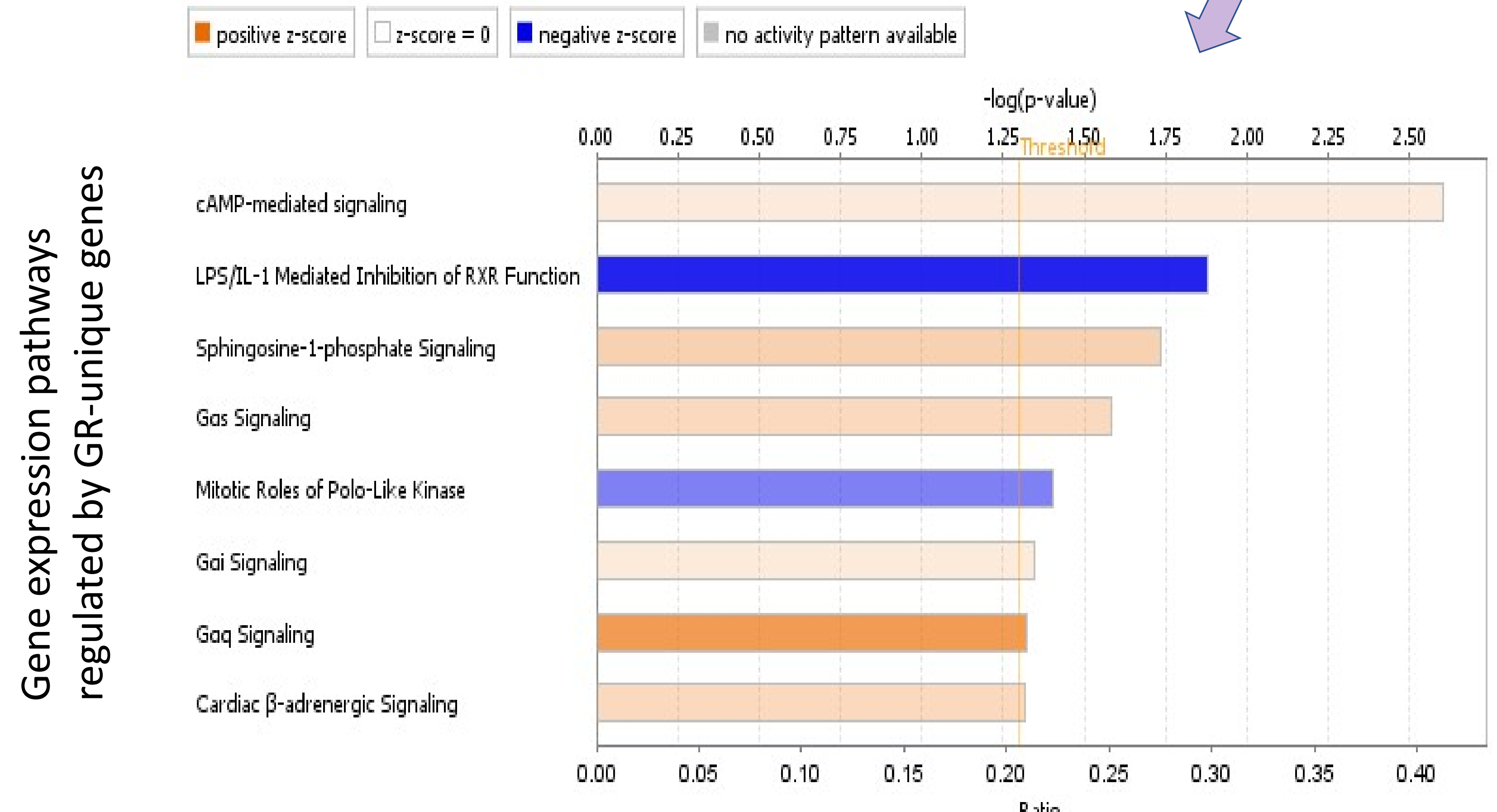

Figure 3. Ingenuity pathway anais
vsV). (unpublished Long et

GR activation regulates expression of Phosphodiesterases
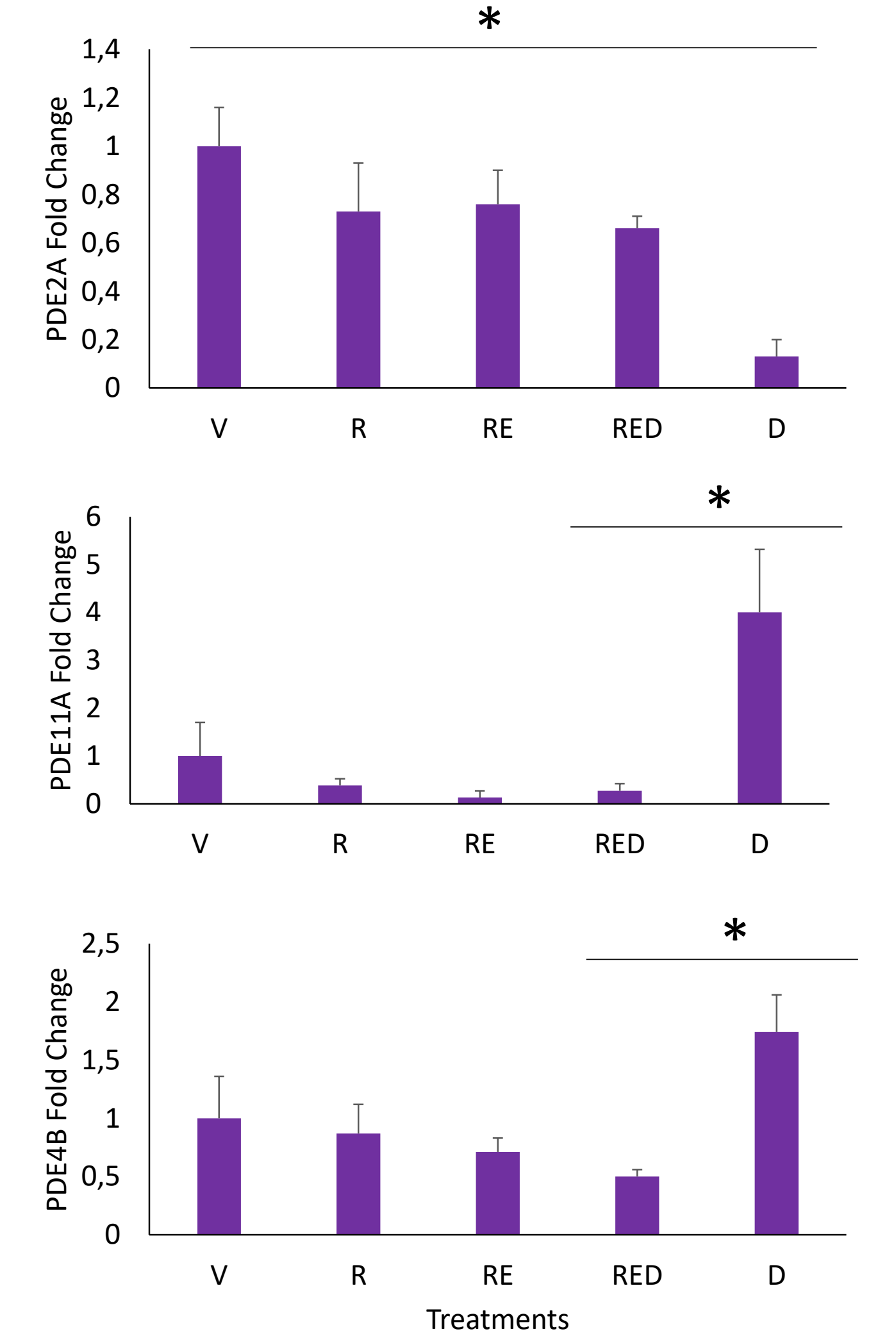

Figure 4. This figure depicts the level of PDE2A, PDE11A, and PDE4B mRNA expression in 22 Rv1 cells compared to the level of Beta-Actin mRNA expression. * ${ }^{*}<0.05$

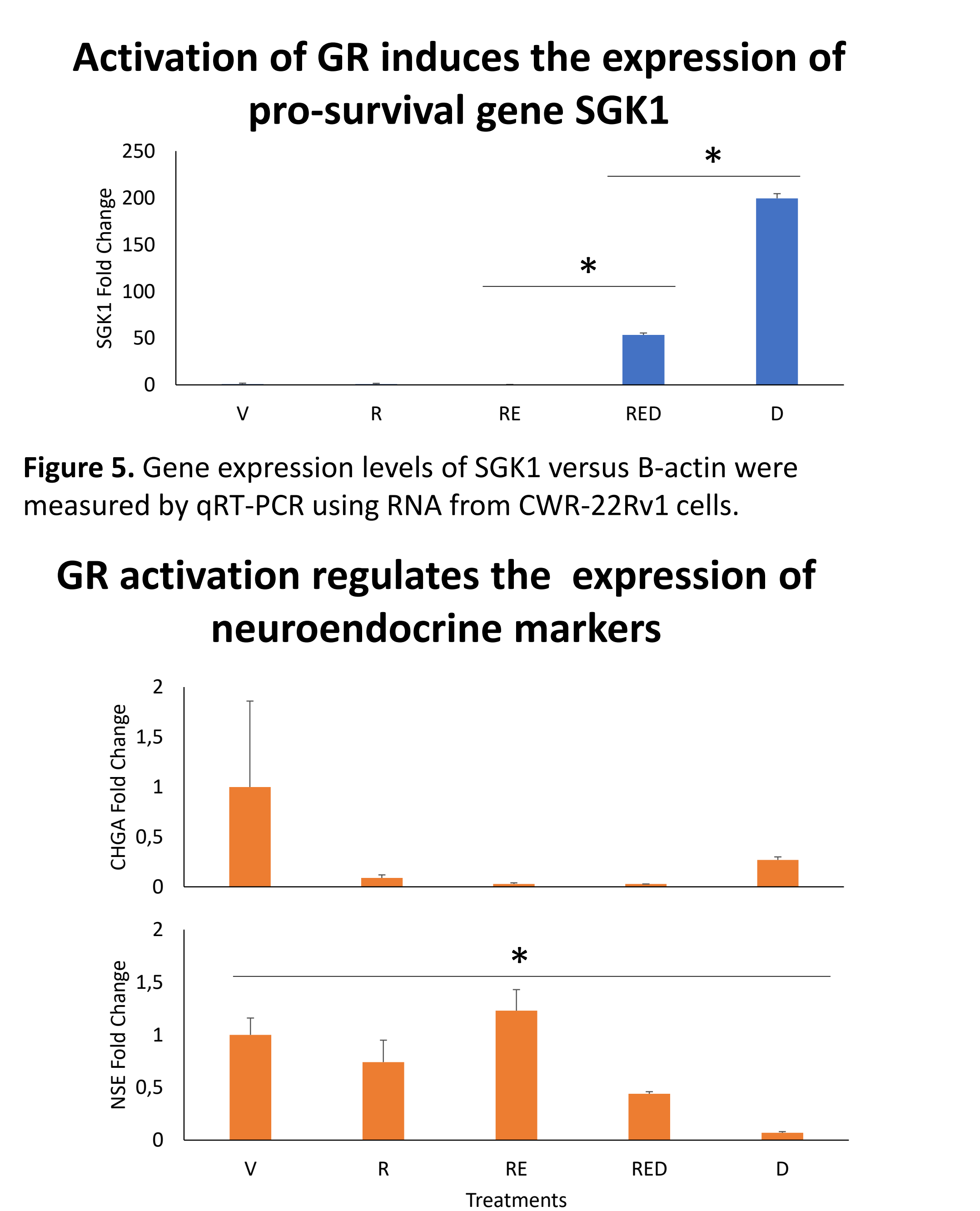

Figure 6. Gene expression levels of CHGA and NSE versus B-actin were
Results

Cell Growth following treatment

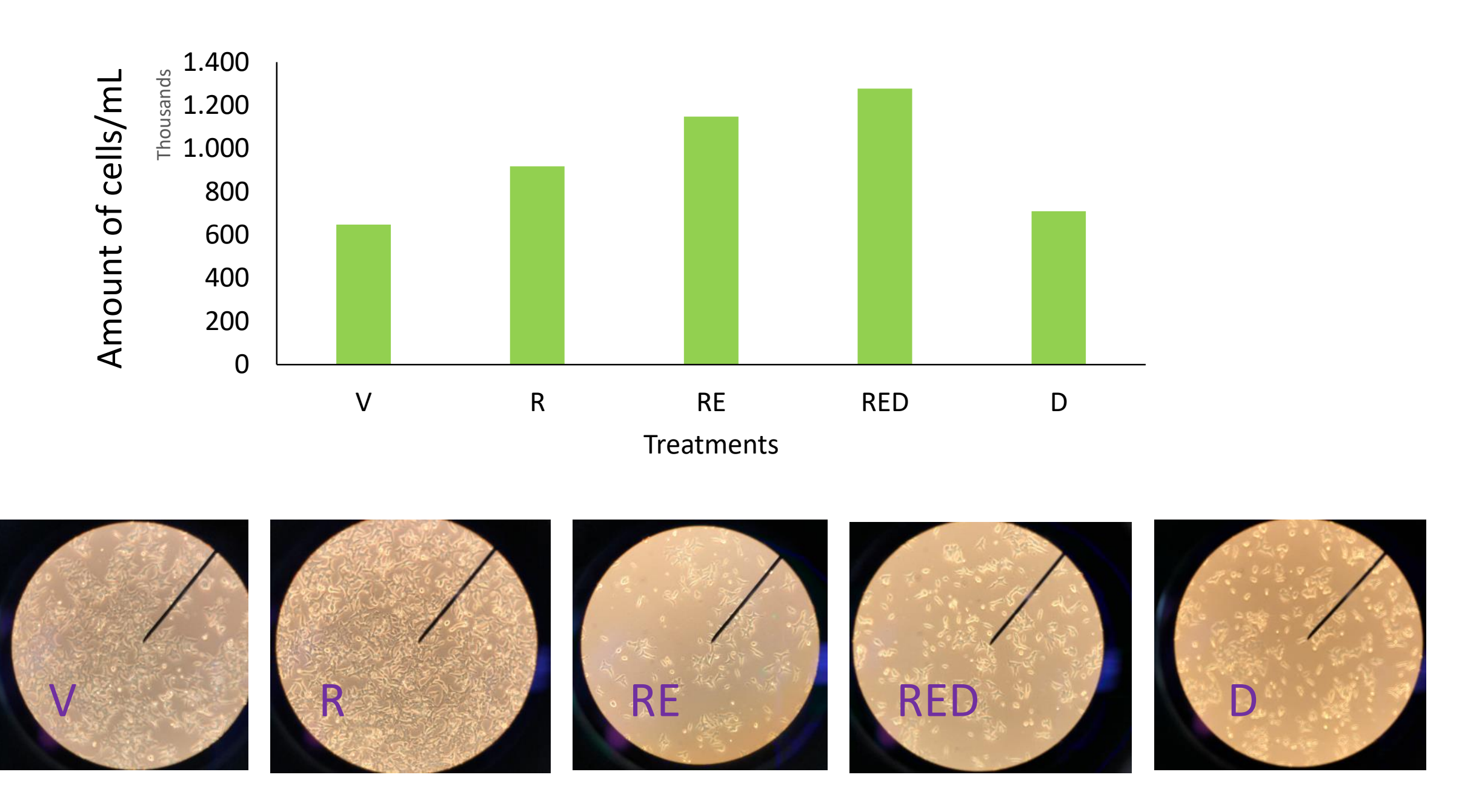

Figure 7. The bar graph represents CWR-22Rv1 cell counts after 3 days of

\section{Findings}

GR is highly expressed in CRPC compared to primary PC

The majority of GR-regulated genes do not overlap with ARregulated genes

Gene expression pathways including cAMP signaling pathwary are regulated by GR but not by $A R$

The expression of phosphodiesterases, which play a role in CAMP signaling, are regulated by GR

SGK1, a pro-survival gene, is dramatically upregulated by GR

with or without the presence of AR-signalin

Neuroendocrine marker are GR-regulated

\section{Summary}

Glucocorticoid receptor (GR) expression is increased in castrateindicating that $G R$ activity increases after androgen deprivation.

GR-activation in androgen receptor (AR)-blocked cells induces different genes than AR, suggesting that GR-driven CRPC is unique different genes than AR, suge
from AR-driven disease.

mechanisms by which GR drives PC progression may reveal therapeutic targets for advanced $\mathrm{PC}$

\section{References \\ - Long, TM et al. "Selective Glucocorticoid Receptor Modulators (SGRMs) Delay Castrate-Resistant Prostate Cancer Growth" Molecular Cancer Therapeutics, 20 Apr. 2017. \\ - Pal, SK et al. "Enzalutamide for the treatment of prostate cancer." Expert Opin Pharmacother, 27 Feb. 2013 \\ - Sapio, L et al. "Targeting protein kinase A in cancer therapy: an update." EXCLI J, 18 Aug, 2014. \\ Acknowledgements}

Collaborators: University of Chicago Department of Medicine Mentor: Dr. Tiha M. Long

Funding Source: Office of Student Research at Roosevelt Universty, Department of Biological, Physical, and Health Sciences at Roosevelt 